\title{
The relationship between sleep and behavior in autism spectrum disorder (ASD): a review
}

\author{
Simonne Cohen ${ }^{1 *}$, Russell Conduit ${ }^{2}$, Steven W Lockley ${ }^{1,3,4}$, Shantha MW Rajaratnam ${ }^{1,3,4}$ and Kim M Cornish ${ }^{1 *}$
}

\begin{abstract}
Although there is evidence that significant sleep problems are common in children with autism spectrum disorder (ASD) and that poor sleep exacerbates problematic daytime behavior, such relationships have received very little attention in both research and clinical practice. Treatment guidelines to help manage challenging behaviors in ASD fail to mention sleep at all, or they present a very limited account. Moreover, limited attention is given to children with low-functioning autism, those individuals who often experience the most severe sleep disruption and behavioral problems. This paper describes the nature of sleep difficulties in ASD and highlights the complexities of sleep disruption in individuals with low-functioning autism. It is proposed that profiling ASD children based on the nature of their sleep disruption might help to understand symptom and behavioral profiles (or vice versa) and therefore lead to better-targeted interventions. This paper concludes with a discussion of the limitations of current knowledge and proposes areas that are important for future research. Treating disordered sleep in ASD has great potential to improve daytime behavior and family functioning in this vulnerable population.
\end{abstract}

Keywords: Autism spectrum disorder, Low-functioning autism, Sleep difficulties in ASD, Treating sleep in ASD

\section{Review}

Autism spectrum disorder (ASD) is a developmental disorder characterized by deficits in social communication and repetitive and stereotyped interests and behaviors [1]. Autism is among the most enigmatic disorders of child development, with a dramatic increase in prevalence from 1 in 88 children in 2008 to 1 in 68 children in 2010 [2]. While the global burden of ASD is currently unknown, in the United States, the annual societal cost of the condition was recently predicted to be $\$ 126$ billion and $\$ 34$ billion in the UK [3]. This escalation and economic burden identify individuals with ASD as one of the highest priority populations for clinical research and treatment development.

Currently, one of the most burdensome complaints among parents of children with autism is disrupted sleep, with more than $40-80 \%$ of children experiencing sleep problems, compared with $25-40 \%$ in typically developing children (TYP) [4,5]. In a developing child, sleep serves multiple functions, including energy conservation,

\footnotetext{
* Correspondence: simonne.cohen@monash.edu; kim.cornish@monash.edu 'School of Psychological Sciences, Faculty of Biomedical and Psychological Sciences, Monash University, Melbourne, Australia

Full list of author information is available at the end of the article
}

brain growth, memory consolidation, and cognition [6]. Given the importance of sleep in daily functioning, the consequence of disrupted sleep in individuals with ASD is potentially serious. Recent research has shown that insufficient sleep exacerbates the severity of core ASD symptoms (e.g., repetitive behaviors, social and communication difficulties) $[7,8]$, as well as other maladaptive behaviors (e.g., self-injury, tantrums, and aggression) $[9,10]$. To date, however, the relationship between sleep profiles and behavioral problems in individuals with ASD is limited. Current sleep treatments fail to target the specific nature of deficits in individuals with low-functioning autism. In this paper, we emphasize that the identification sleep profiles in children with low-functioning autism are necessary to identify targeted interventions, particularly for challenging behaviors in this disorder. This review concludes with methodological considerations and offers suggestions for future research designed to more clearly understand disrupted sleep so as to provide targeted treatments in this population.

\section{Low-functioning autism}

ASD is characterized by notable phenotypic heterogeneity, which is often viewed as an obstacle to the study of 
etiology, diagnosis, treatment, and prognosis [11]. The degree of impairment among individuals with ASD is variable, thereby requiring the distinction between individuals with low-functioning autism and high-functioning autism, defined as those which have an intellectual quotient that is below average $(<70)$ and above average $(\geq 70)$, respectively [1]. What the current DSM-V fails to capture is that individuals with low-functioning autism experience significantly graver impairments than those experienced by their higher functioning counterparts [12]. In addition to displaying core symptoms of ASD, many children with low-functioning autism may exhibit serious behavioral disturbances such as tantrums, aggression, environmental destruction, socially inappropriate behavior, and self-injurious behavior [13]. Therefore, a child with low-functioning autism is likely to have a much more complex diagnostic picture, including a greater severity of ASD symptoms and associated co-morbidities and often require life-long extensive support. To date, these groups of individuals have not received comparable attention compared to individuals with high-functioning autism. This paper argues that these groups of individuals should be the focus of future research as they are most in need of treatment.

\section{Sleep difficulties in autism spectrum disorder}

ASD is frequently accompanied by co-morbid disorders and associated problems, one of which is sleep disruption $[14,15]$. One of the most burdensome and profound complaints among parents and caregivers of children with ASD is poor sleep. Research suggests that about $40-80 \%$ of individuals with an ASD experience a sleep problem, and the risk appears to be unrelated to the severity of cognitive impairment [16]. Other researchers have shown that individuals with low-functioning autism have a higher predisposition to chronic sleep-wake cycle disturbances when compared to higher-functioning individuals, given the degree and severity of their cognitive impairment [17]. This paper argues that understanding, identifying, and treating sleep disorders in low-functioning autism may impact favorably on associated conditions and daytime behavior and therefore improve the quality of life in this population.

\section{Heterogeneity of sleep difficulties in ASD}

Since ASD is considered to be a multifaceted disorder reflected in different symptom profiles across individuals, it is not surprising that a multitude of sleep problems are prevalent in this population. Moreover, the variability of sleep profiles in ASD is suggestive of the mixed phenotypic profiles of ASD samples. Among children with ASD, the most common sleep issues are prolonged sleep latency, decreased sleep efficiency, reduced total sleep time, increased waking after sleep-onset, bedtime resistance, and daytime sleepiness; see [18] for a review. Accordingly, there does not appear to be one particular sleep problem that characterizes children with ASD, but many. These sleep difficulties appear to persist throughout the lifespan [19] and individuals with ASD who experience one sleep problem will often experience co-existing sleep problems [20]. Several of these sleep difficulties can be classified according to the International Classification of Sleep Disorders (ICSD-3) as primary sleep disorders (e.g., insomnia, parasomnia, and circadian rhythm sleep-wake disorders) [21]. In Table 1, the most common sleep problems in ASD have been reported against the ICSD-3 broad criteria for classifying sleep disorders in order to give a sense of the range and scope of sleep difficulties that are present in ASD. To date, most of the studies exploring sleep in ASD have focused on individuals with highfunctioning autism, those individuals who have an ability to communicate and cooperate during actigraphy and polysomnography sleep studies [22]. Currently, there is an inconsistent understanding of the nature and prevalence of sleep difficulties in low-functioning autism. One study has suggested that the severity of sleep problems (such as sleep-onset delay and sleep duration) increases with the severity of autism symptoms (such as communication deficits) [8]. Another study has suggested that increased autism severity predicts an increased likelihood of sleep problems [23]; however, these links are still speculative, and sleep profiles in low-functioning autism are yet to be elucidated. To date, it is still unclear what specific sleep problems and symptom relationships are unique to individuals with low-functioning autism.

\section{The complex etiology of sleep disturbances in individuals with ASD}

Although highly prevalent and persistent, the etiology of sleep problems in children with ASD remains uncertain [41]. Several theories have been put forward to suggest that sleep disruption may be a direct result of either i) the ASD condition or ii) other associated co-morbidities. Research has suggested that the underlying neurophysiology and neurochemistry may predispose individuals with ASD to have chronic sleep-wake disturbances. The development of circadian rhythms, which is established within 12-16 weeks of birth, requires the perception of the environmental time cues ("zeitgebers") to permit appropriate entrainment with the 24-h day (i.e., the synchronization of the internal biological clock to external time cues). The most powerful time cue is the 24-h light/dark cycle, but non-photic time cues such as timing of meals and social contacts can also have influence. Where brain damage or maldevelopment has occurred such as in ASD, these entrainment pathways may be impaired [19]. Children with low-functioning autism are subject to many variables that can potentially affect circadian entrainment, including decreased sensitivity to 
Table 1 ICSD-3 Classification of sleep disorders in children with ASD including descriptions and evidence

\begin{tabular}{|c|c|c|c|c|}
\hline $\begin{array}{l}\text { ICSD-3 } \\
\text { Classification }\end{array}$ & Sleep profile & Study & $\begin{array}{l}\text { Sleep } \\
\text { measures }\end{array}$ & Significant findings in ASD population \\
\hline \multirow[t]{9}{*}{ Insomnia } & \multirow{9}{*}{$\begin{array}{l}\text { Persistent difficulty with sleep initiation, } \\
\text { maintenance, duration, consolidation, or quality. } \\
\text { Includes bedtime resistance, frequent night } \\
\text { awakenings, and/or an inability to sleep independently }\end{array}$} & Wiggs et al. [24] & $\begin{array}{l}\text { Actigraphy } \\
\text { and SQ }\end{array}$ & $\begin{array}{l}\text { Increased sleep latency, night } \\
\text { awakenings, and poor sleep efficiency }\end{array}$ \\
\hline & & Malow et al. [25] & $\begin{array}{l}\text { PSG and } \\
\text { CSHQ }\end{array}$ & $\begin{array}{l}\text { Poorer sleep efficiency, longer sleep } \\
\text { latency, and frequent night awakenings } \\
\text { (up to } 2-3 \text { h) }\end{array}$ \\
\hline & & $\begin{array}{l}\text { Goodlin-Jones et al. } \\
\text { [26] }\end{array}$ & $\begin{array}{l}\text { Actigraphy } \\
\text { and SD }\end{array}$ & $\begin{array}{l}\text { Less total sleep time (TST) compared to } \\
\text { TYP children or those with a DD }\end{array}$ \\
\hline & & Krakowiak et al. [27] & SQ & $\begin{array}{l}\text { Higher sleep-onset factor scores and } \\
\text { night awakenings compared to } \\
\text { typical children }\end{array}$ \\
\hline & & Souders et al. [28] & $\begin{array}{l}\mathrm{CSHQ}, \mathrm{SD}, \\
\text { and } \\
\text { actigraphy }\end{array}$ & $\begin{array}{l}\text { Behavioral insomnia evident in } 66 \% \\
\text { of children with ASD compared to } \\
45.9 \% \text { in controls }\end{array}$ \\
\hline & & Anders et al. [29] & $\begin{array}{l}\text { Actigraphy } \\
\text { and SD }\end{array}$ & $\begin{array}{l}\text { ASD children aged } 2-5 \text { years slept } \\
\text { less per } 24-h \text { period on average } \\
\text { compared to controls }\end{array}$ \\
\hline & & Giannotti et al. [30] & $\begin{array}{l}\text { PSG and } \\
\text { CSHQ }\end{array}$ & $\begin{array}{l}\text { Children with regressive ASD }(n=18) \text { had } \\
\text { greater bedtime resistance, sleep-onset } \\
\text { latency, and less TST than controls }\end{array}$ \\
\hline & & Sivertsen et al. [31] & $\begin{array}{l}\text { Parent } \\
\text { report }\end{array}$ & $\begin{array}{l}\text { Prevalence of chronic insomnia was ten } \\
\text { times higher in children with ASD } \\
\text { symptoms compared to controls }\end{array}$ \\
\hline & & Baker et al. [32] & $\begin{array}{l}\text { Actigraphy } \\
\text { and SD }\end{array}$ & $\begin{array}{l}\text { Adolescents with ASD were three times } \\
\text { more likely to have symptoms of } \\
\text { insomnia than their TYP peers }\end{array}$ \\
\hline \multirow[t]{5}{*}{ Parasomnias } & \multirow{5}{*}{$\begin{array}{l}\text { Undesirable physical experiences which occur } \\
\text { within sleep or during arousal from sleep. } \\
\text { Includes nightmares, wake screaming, complex } \\
\text { movements, dreams, and automatic nervous } \\
\text { system activity }\end{array}$} & Hering et al. [33] & $\begin{array}{l}\text { Actigraphy } \\
\text { and SQ }\end{array}$ & $\begin{array}{l}54 \% \text { of children with ASD had multiple } \\
\text { and early night arousals }\end{array}$ \\
\hline & & Doo et al. [34] & $\mathrm{SQ}, \mathrm{CSHQ}$ & All reported evidence of higher rates \\
\hline & & Schreck et al. [35] & $\begin{array}{l}\text { and } \\
\text { actigraphy }\end{array}$ & $\begin{array}{l}\text { of parasomnias in children with ASD } \\
\text { compared to comparison groups }\end{array}$ \\
\hline & & Liu et al. [20] & & \\
\hline & & Goldman et al. [36] & $\mathrm{CSHQ}$ & $\begin{array}{l}\text { Younger children with ASD had more } \\
\text { parasomnias than older children }\end{array}$ \\
\hline \multirow[t]{4}{*}{$\begin{array}{l}\text { Circadian } \\
\text { rhythm sleep- } \\
\text { wake } \\
\text { disorders }\end{array}$} & \multirow[t]{4}{*}{$\begin{array}{l}\text { Alterations of the circadian time-keeping system, its } \\
\text { entrainment mechanisms, or misalignment of the } \\
\text { endogenous circadian rhythm and the external } \\
\text { environment. Manifests in } \\
\text { difficulty initiating and maintaining sleep }\end{array}$} & Giannotti et al. [37] & $\begin{array}{l}\text { PSG and } \\
\text { CSHQ }\end{array}$ & $\begin{array}{l}\text { More than } 10 \% \text { of children with ASD } \\
\text { were found to have sleep problems } \\
\text { that varied by season due to fluctuations } \\
\text { in light/dark cycles }\end{array}$ \\
\hline & & Tordjman et al. [38] & $\begin{array}{l}\text { Measures } \\
\text { of } \\
\text { melatonin }\end{array}$ & $\begin{array}{l}\text { Elevated daytime and lower nocturnal } \\
\text { melatonin in individuals with ASD } \\
\text { compared with controls }\end{array}$ \\
\hline & & Hayashi [39] & \multirow{2}{*}{$\begin{array}{l}\mathrm{SD}, \mathrm{CSHQ} \\
\text { and PEQ }\end{array}$} & \multirow{2}{*}{$\begin{array}{l}\text { "Free-running" sleep (not entrained to } \\
\text { 24-h), sleep-onset delay, and early } \\
\text { morning awakening in children } \\
\text { with ASD }\end{array}$} \\
\hline & & Segawa [40] & & \\
\hline
\end{tabular}

CSHQ Child Sleep Habit Questionnaire, DD developmental disability, TYP typical development, PEQ Parenting Events Questionnaire, PSG polysomnography, SD sleep diary, SQ Sleep Questionnaire.

social cues, and possible misalignment between circadian phase and imposed light/dark cycles due to variations in light sensitivity [42]. There is also evidence of biological abnormalities in the timing of melatonin secretion (a neurohormone which regulates the sleep-wake cycle). Studies have shown elevated daytime melatonin and significantly less nocturnal melatonin in individuals with ASD compared to controls [43]. Other studies have found variability in melatonin production with some individuals having normal melatonin profiles, suggesting that there is a subgroup of individuals with ASD that may have a dysregulation in their circadian rhythms $[43,44]$. It is also important to note that melatonin abnormalities have been found in several other disorders with intellectual disability $[45,46]$, raising the issue of non-specificity of the melatonin findings in ASD [38]. Nevertheless, early speculations suggest that the influence on melatonin and altered rhythms in a subset of 
children with ASD may lead to differences in sleep schedules and result in perceived problematic behavior around bedtime and morning routines.

Other theories have been put forward to suggest that sleep disruption may be a secondary condition influenced by other co-occurring medical and psychiatric conditions that are present in ASD. Gastrointestinal disorders (GI) are common in ASD children with more than $50 \%$ of children experiencing constipation or diarrhea, often resulting in induced toilet awakenings throughout the night [47]. Seizures and epilepsy are also common in children with low-functioning autism (6-60\%), and research has shown that sleep deprivation can often facilitate seizures, and conversely, seizures adversely affect sleep architecture [48]. Children with ASD are also $25-70 \%$ more likely to have co-morbid psychiatric conditions such as anxiety and attention-deficit/hyperactivity disorder (ADHD), displaying symptoms of inattention and high levels of arousal such as hyperactivity [49]. These conditions influence presleep arousal, significantly delayed sleep onset, and over time may be linked to the development of insomnia [50]. Medications known to treat medical and behavioral conditions, such as antipsychotics and serotonin reuptake inhibitors (SSRIs) may also disrupt the sleep-wake cycle in ASD [18]. Understanding the nature of sleep disturbances in ASD is a complex dynamic process whereby there is a multi-directional relationship between sleep and certain factors. Further exploration of such relationships may elucidate mechanisms, which may in turn suggest effective treatment strategies to reduce sleep symptoms in individuals with low-functioning autism.

\section{Treating sleep disruptions in children with ASD}

There is increasing evidence of severe sleep problems in children with autism, although little research exists for evidence-based sleep treatments within this population [51]. Sleep disorders in ASD often remain untreated and ignored as other behavioral difficulties tend to take precedence [52]. Some research supports the efficacy of melatonin in decreasing sleep-onset latency and increasing total sleep time when administered close to bedtime $[53,54]$. In contrast, studies have suggested that melatonin is only effective for children with ASD who have difficulties with sleep latency, as it is known to increase night awakenings and disrupt sleep maintenance [55]. Additionally, the effectiveness of melatonin is influenced by the type of sleep disturbance, environmental factors, and other associated medical conditions [56]. After excluding biological factors, parent-based education and behavioral interventions are the first line of treatment for sleep disruption in ASD [57]. Behavioral interventions such as sleep hygiene approaches which focus on changing the environment in order to promote regular sleepwake cycle have been shown to be effective interventions in improving sleep onset and maintenance in ASD [58]. The basic principles of sleep hygiene include selecting an appropriate bedtime and set routine, minimizing television watching, and reducing emotional and behavioral stimulation at night [16]. This behavioral treatment approach is optimal for individuals with low-functioning autism who on average have minimal or no verbal skills. Currently, however, the efficacy of behavioral treatment approaches is based on small studies and lack objective sleep measures and has been performed with the inclusion of children having a variety of diagnoses not limited to ASD [59]. Light therapy is effective in advancing or delaying the sleep phase in patients with circadian sleep disorders and can be considered for children with an ASD who present with circadian dysfunction [16]; however, there is limited research available with light therapy with individuals with low-functioning autism. Given the associations between inadequate sleep, intensified daytime problem behaviors, and parental stress in ASD, there is a strong need to develop effective sleep interventions adapted to a child's cognitive and developmental level.

\section{The relationship between poor sleep and challenging behaviors in ASD}

In typical development, sleep disruption is associated with emotional and behavioral problems such as internalizing and externalizing symptoms [60]. Moreover, a growing body of evidence shows that childhood sleep disturbances may widely impact children's health, behavior, attention, cognition, and school performance [61]. Given the nature of autism and its associated challenging behaviors, the effects of sleep disruption in this disorder are potentially serious. Sleep problems have been found to exacerbate ASD symptoms. Fewer hours of sleep have been shown to correlate with and predict greater ASD severity such as social skill deficits [41], communication impairments, higher rates of stereotypic behaviors, and stricter adherence to non-functional routines [62]. In addition to exacerbating ASD symptoms, sleep difficulties have been shown to be associated with increased rates of overactivity, disruption, non-compliance, aggression, irritability, and affective problems, which are all problems that could significantly interfere with daytime functioning in ASD [19,25,62,63]. Table 2 summarizes studies conducted to date exploring the relationship between sleep and challenging behaviors, ordered by date of publication, and summarized by their method, significant findings, and effect sizes. Despite the research exploring the relationship between sleep difficulties and challenging behavior in ASD, the influence of sleep problems in children with low-functioning autism has been neglected. Moreover, limited research has been conducted on the bi-directional relationship between sleep and behavior in these individuals. 
Table 2 Studies exploring the relationship between sleep and challenging behaviors in ASD

\begin{tabular}{|c|c|c|c|c|c|}
\hline Study & $\begin{array}{l}\text { Type of } \\
\text { study }\end{array}$ & Participants & Measurements & Significant findings & $\begin{array}{l}\text { Effect sizes } \\
(r)^{1}\end{array}$ \\
\hline Schreck et al. [62] & $\begin{array}{l}\text { Cross } \\
\text { sectional }\end{array}$ & $\begin{array}{l}55 \text { parents of children with mixed ASD } \\
\text { functioning aged } 5-12 \text { years }\end{array}$ & GARS, BEDS, and PSQ & $\begin{array}{l}\text { Fewer hours of sleep per night predicted ASD severity score, } \\
\text { social skill deficit, and stereotypic behavior }\end{array}$ & $0.33-0.34^{b}$ \\
\hline Liu et al. [20] & $\begin{array}{l}\text { Cross } \\
\text { sectional }\end{array}$ & $\begin{array}{l}27 \text { children with ASD symptoms, and } 32 \text { with } \\
\text { other DD }(M=8.8)\end{array}$ & ADOS, CHSQ, and PSQ & $\begin{array}{l}\text { Hypersensitivity to stimuli, younger age, co-sleeping, medication, } \\
\text { epilepsy, history of sleep problems, and ADHD was associated } \\
\text { with sleep problems in individuals with ASD }\end{array}$ & $0.09^{\mathrm{a}}-0.31^{\mathrm{b}}$ \\
\hline $\begin{array}{l}\text { DeVincent et al. } \\
\text { [64] }\end{array}$ & $\begin{array}{l}\text { Cross } \\
\text { sectional }\end{array}$ & $\begin{array}{l}\text { Parents of children with PDD }(n=112) \text { and TYP }(n \\
=497) \text { aged } 3-5\end{array}$ & $\begin{array}{l}\text { Early childhood inventory-4 } \\
\text { and PSQ }\end{array}$ & $\begin{array}{l}\text { PDD children with sleep problems had higher rates of } \\
\text { ADHD, oppositional behavior, and psychiatric symptoms } \\
\text { compared to children without sleep problems }\end{array}$ & $0.22-0.26^{\mathrm{a}}$ \\
\hline $\begin{array}{l}\text { Goodlin-Jones } \\
\text { et al. [65] }\end{array}$ & $\begin{array}{l}\text { Cross } \\
\text { sectional }\end{array}$ & $\begin{array}{l}68 \text { HFASD children, matched to } 57 \text { with DD, } 69 \\
\text { TYP, aged 24-69 months }\end{array}$ & $\begin{array}{l}\text { Actigraphy, MELC, VABC, } \\
\text { ADOS, ADIR, MSEL, SD, } \\
\text { CSHQ, ESS, and CBCL }\end{array}$ & $\begin{array}{l}\text { Controlling for diagnosis and age, night-time sleep } \\
\text { problems determined by parent report were significantly associated } \\
\text { with decrements in daytime behavior }\end{array}$ & $0.30-0.43^{b}$ \\
\hline Mayes et al. [66] & $\begin{array}{l}\text { Cross } \\
\text { sectional }\end{array}$ & $\begin{array}{l}\text { Parents of } 477 \text { children with a range of ASD } \\
\text { diagnoses (aged 1-15) }\end{array}$ & $\begin{array}{l}\text { CARS, PBS, PSQ, WISC, } \\
\text { WPPSI, and GDS }\end{array}$ & $\begin{array}{l}\text { Sleep problems increased with severity of ASD symptoms. } \\
\text { Oppositional behavior, aggression, ADHD, and mood variability } \\
\text { predicted sleep disturbance in ASD }\end{array}$ & $0.59^{c}$ \\
\hline $\begin{array}{l}\text { Goldman et al. } \\
{[67]}\end{array}$ & $\begin{array}{l}\text { Cross } \\
\text { sectional }\end{array}$ & $\begin{array}{l}42 \text { mixed ASD samples and } 16 \text { TYP children aged } \\
4-10 \text { years }\end{array}$ & $\begin{array}{l}\text { PCQ, CSHQ, RBS-R, CBCL, } \\
\text { PSG, and Actigraphy }\end{array}$ & $\begin{array}{l}\text { Poor sleepers with ASD had more ADHD symptoms } \\
\text { and more restricted and repetitive behaviors (RRBs) than good } \\
\text { sleepers. Sleep fragmentation was correlated with more RRBs }\end{array}$ & $0.48^{b}-0.69^{c}$ \\
\hline Moon et al. [68] & Case study & $\begin{array}{l}3 \text { children (aged 8-9 years) diagnosed with an } \\
\text { ASD }\end{array}$ & $\begin{array}{l}\text { Actigraphy, SD, CSHQ, } \\
\mathrm{CBCL} \text {, and PSQ }\end{array}$ & $\begin{array}{l}\text { Daytime behavior improved for } 2 / 3 \text { ASD patients following an } \\
\text { intensive sleep treatment }\end{array}$ & $x$ \\
\hline $\begin{array}{l}\text { Rzepecka et al. } \\
{[69]}\end{array}$ & $\begin{array}{l}\text { Cross } \\
\text { sectional }\end{array}$ & $\begin{array}{l}187 \text { parents with child aged } 5-18 \text { years with an ID } \\
\text { and/or ASD from Scotland }\end{array}$ & $\begin{array}{l}\text { ADOS, CSHQ, SCAS-P, and } \\
\text { ABC }\end{array}$ & $\begin{array}{l}\text { Sleep problems were the highest predictor of challenging } \\
\text { behaviors in ASD }\end{array}$ & $0.62^{c}$ \\
\hline $\begin{array}{l}\text { Henderson et al. } \\
{[9]}\end{array}$ & $\begin{array}{l}\text { Cross } \\
\text { sectional }\end{array}$ & $\begin{array}{l}\text { Parents of children aged } 6-12 \text { years with ASD, } \\
\text { Asperger's }(n=58) \text {, and non-ASD }(n=57)\end{array}$ & $\begin{array}{l}\text { CSBQ, CRQ, BRQ, CSHS, } \\
\text { CSWS, and CBCL }\end{array}$ & $\begin{array}{l}\text { In the ASD group, poor sleep quality and hygiene were } \\
\text { related to higher levels of externalizing behaviors }\end{array}$ & $0.60^{c}$ \\
\hline $\begin{array}{l}\text { Goldman et al. } \\
{[10]}\end{array}$ & $\begin{array}{l}\text { Cross } \\
\text { sectional }\end{array}$ & $\begin{array}{l}\text { Parents of } 1,784 \text { children, ages } 2-18 \text { with high- } \\
\text { functioning autism (USA) }\end{array}$ & $\mathrm{ADOS}, \mathrm{CHSQ}$, and PCQ & $\begin{array}{l}\text { Poor sleepers had a higher percentage of behavioral } \\
\text { problems on all PCQ scales (e.g., aggression, RRBs, stereotypy, } \\
\text { and hyperactivity) than good sleepers }\end{array}$ & $0.11^{\mathrm{a}}-0.34^{\mathrm{b}}$ \\
\hline Sikora et al. [70] & $\begin{array}{l}\text { Cross } \\
\text { sectional }\end{array}$ & $\begin{array}{l}\text { Parents of 1,193 children with mixed ASD } \\
\text { diagnosis aged } 4-10 \text { years (USA) }\end{array}$ & CSHQ, VABS, and MSEL & $\begin{array}{l}\text { Moderate-severe sleep problems in ASD resulted in higher } \\
\text { daytime externalizing behavior and poorer adaptive skills than } \\
\text { those with ASD with no sleep problems }\end{array}$ & $x$ \\
\hline Anders et al. [71] & $\begin{array}{l}\text { Cross } \\
\text { sectional }\end{array}$ & $\begin{array}{l}\text { Parents of children with an ID }(n=57) \text {, ASD ( } n= \\
68) \text {, and TYP }(n=69) \text {, aged } 24-66 \text { months }\end{array}$ & $\begin{array}{l}\text { ADOS, ADIR, MSEL, CBCL, } \\
\text { actigraphy, CSHQ, and WISC }\end{array}$ & $\begin{array}{l}\text { Parent-reported sleep problem but not actigraphy recordings } \\
\text { were associated with more core behavior problems in ASD }\end{array}$ & $0.12^{a}-0.39^{b}$ \\
\hline Tudor et al. [8] & $\begin{array}{l}\text { Cross } \\
\text { sectional }\end{array}$ & $\begin{array}{l}\text { Parents of } 109 \text { children with a diagnosis of ASD } \\
\text { (aged 3-18 years) }\end{array}$ & $\begin{array}{l}\text { CSHQ, GARS, and PECS } \\
\text { board }\end{array}$ & $\begin{array}{l}\text { Sleep-onset delay and duration was positively correlated } \\
\text { with ASD severity and symptoms and was the strongest predictor of } \\
\text { communication deficits and stereotypic behavior }\end{array}$ & $0.34^{b}-0.51^{c}$ \\
\hline Park et al. [7] & $\begin{array}{l}\text { Cross } \\
\text { sectional }\end{array}$ & $\begin{array}{l}\text { Parents of } 166 \text { ASD children and } 111 \text { unaffected } \\
\text { siblings aged } 4-15 \text { years from Korea }\end{array}$ & $\begin{array}{l}\text { ADIR, ADOS, CSHQ, WISC, } \\
\text { and K-CBCL }\end{array}$ & $\begin{array}{l}\text { Communication abnormalities and RRBs were associated with } \\
\text { increased risk of sleep problems in ASD. ASD individuals } \\
\text { had higher, internalizing, and externalizing problems compared } \\
\text { to their unaffected siblings }\end{array}$ & $0.31-0.43^{b}$ \\
\hline
\end{tabular}


Table 2 Studies exploring the relationship between sleep and challenging behaviors in ASD (Continued)

\begin{tabular}{|c|c|c|c|c|c|}
\hline Taylor et al. [72] & $\begin{array}{l}\text { Cross } \\
\text { sectional }\end{array}$ & $\begin{array}{l}\text { Parents of children with an ASD }(n=335) \text { aged } \\
1-10 \text { years }(M=5.5)\end{array}$ & $\begin{array}{l}\text { BEDS, WISC, WPPSI, MSEL, } \\
\text { SIB-R, and VABS }\end{array}$ & $\begin{array}{l}\text { Children who slept fewer hours per night had lower IQ, verbal } \\
\text { skills, adaptive functioning, socialization, and communication skills }\end{array}$ & $0.40-0.44^{b}$ \\
\hline $\begin{array}{l}\text { Holloway et al. } \\
{[73]}\end{array}$ & $\begin{array}{l}\text { Cross } \\
\text { sectional }\end{array}$ & $\begin{array}{l}\text { 1,583 ASD children from Autism Treatment } \\
\text { Network aged } 2-17 \text { years }\end{array}$ & $\begin{array}{l}\text { CSHQ, VABS, MSEL, } \\
\text { Stanford Binet, CBCL, } \\
\text { ADOS, and SSP }\end{array}$ & $\begin{array}{l}\text { Anxiety, ASD severity, sensory sensitivity, and GI issues all predicted } \\
\text { sleep disturbance. IQ positively predicted sleep disturbance }\end{array}$ & $0.17^{\mathrm{a}}-0.44^{\mathrm{b}}$ \\
\hline $\begin{array}{l}\text { Schwichtenberg } \\
\text { et al. [74] }\end{array}$ & $\begin{array}{l}\text { Cross } \\
\text { sectional }\end{array}$ & $\begin{array}{l}\text { ASD siblings ( } n=104) \text { and families with no history } \\
\text { of ASD }(n=76)\end{array}$ & $\begin{array}{l}\text { MSEL, ADOS, CBCL, and } \\
\text { PCQ }\end{array}$ & $\begin{array}{l}\text { For both groups, sleep problems were associated with elevated } \\
\text { behavior problems (e.g., reactivity, anxiety, somatic complaints, } \\
\text { withdrawal, inattention, and aggression) }\end{array}$ & $0.16-0.21^{a}$ \\
\hline $\begin{array}{l}\text { Mannion et al. } \\
{[47]}\end{array}$ & $\begin{array}{l}\text { Cross } \\
\text { sectional }\end{array}$ & $\begin{array}{l}\text { Parents of } 89 \text { children and adolescents (aged 3- } \\
\text { 16) with mixed ASD subtypes in Ireland }\end{array}$ & ASD-CC, GSI, and CSHQ & $\begin{array}{l}\text { Avoidant behavior, under-eating, and GI symptoms predicted } \\
\text { sleep problems in individuals with an ASD }\end{array}$ & $0.46^{b}-0.50^{c}$ \\
\hline May et al. [75] & Longitudinal & $\begin{array}{l}\text { Gender-matched children with high-functioning } \\
\text { autism }(n=46) \text { and TYP }(n=38) \text { aged } 7-12 \text { years } \\
\text { from Melbourne (Australia) }\end{array}$ & $\begin{array}{l}\text { Conner's third edition, } \\
\text { SCAS, and CSHQ }\end{array}$ & $\begin{array}{l}\text { The ASD group had more sleep disturbance than the TYP group. } \\
\text { Sleep disturbance decreased over the year in children with ASD, } \\
\text { and this was associated with improved social ability }\end{array}$ & $0.41^{b}-0.69^{c}$ \\
\hline $\begin{array}{l}\text { Richdale et al. } \\
{[50]}\end{array}$ & $\begin{array}{l}\text { Cross } \\
\text { sectional }\end{array}$ & $\begin{array}{l}27 \text { adolescents with high-functioning autism } \\
\text { (aged 15-16) and } 27 \text { matched TYP controls }\end{array}$ & $\begin{array}{l}\text { D, actigraphy, CSRQ, CED- } \\
\text { DASS-21, and SAAQ }\end{array}$ & $\begin{array}{l}\text { Sleep variables significantly accounted for } 57 \% \text { of the variance of } \\
\text { daytime functioning symptoms of insufficient sleep in the } \\
\text { high-functioning ASD group }\end{array}$ & $0.75^{c}$ \\
\hline Adams et al. [23] & $\begin{array}{l}\text { Cross } \\
\text { sectional }\end{array}$ & $\begin{array}{l}548 \text { children and adolescents ( } 2-18 \text { years), with } \\
\text { ASD symptoms }\end{array}$ & ASD-CC & $\begin{array}{l}\text { Individuals with severe sleep problems had higher levels of total } \\
\text { challenging behaviors than those with mild sleep problems }\end{array}$ & $-0.47^{\mathrm{b}}$ \\
\hline \multicolumn{6}{|c|}{ 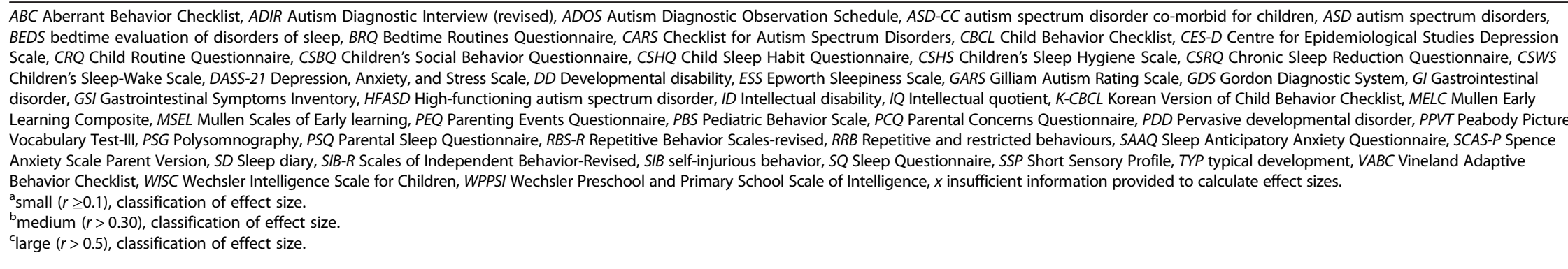 } \\
\hline
\end{tabular}

large $(r>0.5)$, classification of effect size. 


\section{Future directions: the relationship of sleep and behavior in ASD}

\section{Researched areas}

The current research highlights clear uni-directional relationships between sleep and behavior in individuals with an ASD. It is well researched that sleep problems worsen ASD symptomatology across most core domains, as well as exacerbate pre-existing behavioral problems. These relationships have been fairly well investigated in cross-sectional studies using objective measures with individuals with mixed groups of ASD samples and individuals with highfunctioning autism. Objective tools such as polysomnography (a tool that monitors physiological parameters during sleep such as electroencephalogram) and wrist actigraphy (a tool that uses an accelerometer to detect and record muscle activity) have been used successfully to validate relationships between poor sleep and daytime behaviors in a mixed sample of ASD children [51,65,71]. There is also modest evidence to suggest that holistic parent report measures such as the CSHQ is a superior single-item response measure which helps gage overall quality of ASD children's sleep [76]. In light of knowledge about the severity of sleep disorders in ASD, there is evidence to suggest that sleep is amendable to treatment in certain populations with ASD. Studies have shown that parent-based education (behavioral therapy) improves sleep-onset delay in children with highfunctioning autism [59] and that pharmacological treatments such as melatonin is an effective sleep treatment for children with autism [77]. Moreover, treating sleep in a subgroup of individuals with ASD has been shown to improve core ASD symptoms (e.g., communication and socialization impairments) as well as reduce the severity of challenging behaviors in ASD $[38,68]$. Applied behavior analysis (ABA) treatment approach is known to be efficacious for the treatment of challenging behavior in a minority of children with ASD [62]; however, its outcomes are influenced by learning rate and cognitive performance. Given that sleep is implicated in behaviors that affect learning, such as compliance, irritability, hyperactivity, and aggression, there is now more evidence to suggest that sleep is a possible obstacle to ABA treatment success in ASD [62]. Given the bi-directional relationship between challenging behaviors and sleep disturbance in ASD, preliminary evidence suggests that treating sleep disturbances and challenging behavior in isolation may not lead to successful outcomes [50]. The foregoing relationship between sleep problems for children with ASD and daytime inappropriate behavior suggests additional research is required to delineate direct connections among specific sleep problems and the specific daytime behavior patterns that may affect individuals with ASD.

\section{Areas for further research}

Although previous studies have identified clear relationships between poor sleep and challenging behaviors in
ASD, as reviewed above, it is still unclear what specific sleep problems and symptom relationships are unique to individuals with low-functioning autism. As mentioned, current research has primarily focused on individuals on the higher functioning end of the autism spectrum, and individuals with low-functioning autism who potentially have the most severe sleep and behavioral deficits have been relatively ignored in the literature. Studying sleep in children with low-functioning autism presents with unique methodological challenges, namely subjective parent reports confer reporting bias and negative halo effects [78] and individuals have difficulty tolerating objective measures such as PSG and actigraphy tools due to sensory sensitivities and lack of cooperation [76]. Given that the National Sleep Foundation [79] identifies children with ASD as one of the highest priority populations for sleep research, there is a need for more accurate, objective, noninvasive measures of sleep, as well as data from children with low-functioning autism in order to better characterize the quality and quantity of sleep in this population.

Another key limitation of the research to date is that very few studies examine behavioral problems and sleep disturbances in ASD longitudinally, with most studies being cross-sectional. Cross-sectional studies only capture an ASD profile at one specific age presentation, and most studies have combined both children and adolescents in their samples. Little is known about how sleep changes over time in ASD and what factors might be associated with this change, for example, age and stages of development. In ASD, one study found no relation between sleep difficulties and developmental stage (i.e., childhood, adolescents, or adulthood) [66], whereas other studies, albeit cross sectional, have found a decline in sleep difficulties with age similar to typical development [36,37]. The severity of ASD symptoms and behavioral disturbance have been known to wax and wane across development, with some behaviors improving with age [80]. Given that different behavioral profiles occur at particular age ranges and developmental age often does not match chronological age in ASD, there is a need to study relationships through longitudinal designs. Only one study to date has compared the relationship between sleep disturbances and behavior longitudinally, in high-functioning autism and in typically developing controls [75]. Thus, to uncover core ASD phenotypes and link these to sleep profiles, more longitudinal studies are required to trace sleep trajectories in this population to understand what unique variables might influence change. For example, sleep difficulties in ASD may vary according to medication use, environment factors such as seasonal changes, or co-morbidities such as epilepsy or GI issues. It is difficult to determine whether co-occurring conditions cause the behavior problems, maintain existing problems, or exacerbate problems already present in ASD. Studies need to be done to address this poignant question. 
Lastly, treatment guidelines to help manage challenging behaviors in individuals with low-functioning autism often fail to mention sleep at all, or they present a very limited account. Identifying and providing treatment for sleep problems in ASD is imperative for improving sleep, as well as for encouraging more positive prognoses by improving daytime behavior and family functioning in this population. One specific proposal is for researchers to identify factors that result in an ASD phenotype and then design targeted therapeutic interventions to reverse or ameliorate specific deficits. For example, exposure to highly arousing stimuli before bed may increase pre-sleep arousal and sleep-onset latency and result in an increase in self regulatory behaviors (such as self-injurious behaviors) the following day in children with low-functioning autism. Heightened light sensitivity from exposure to blue-enriched light from computer and/or tablet screens might also be linked to circadian timing and melatonin issues, increasing sleep-wake circadian rhythm abnormalities in this population. Sound sensitivity inherent within ASD may be linked to lower waking thresholds, sleep fragmentation, and so on. In this paper, it is proposed that profiling ASD children based on the nature of their sleep disruption might help understand symptom and behavioral profiles (or vice versa) and therefore lead to bettertargeted interventions.

\section{Conclusions}

Although there is reason to believe that serious sleep problems are common in children with ASD and that poor sleep exacerbates problematic daytime behavior, these conclusions are still premature and require further investigation. Gaining more specific insight into the individual nature of sleep difficulties in ASD opens up a novel avenue for designing interventions, as sleep is an area with a potential for remediation. Since sleep is a central mechanism for adaptive functioning (e.g., learning, memory, neuroplasticity), it is highly plausible that sleep deficits play a leading role in the symptoms seen in ASD including the exacerbation of challenging behaviors. To date, however, studies have failed to provide conclusive evidence about the relationship between sleep and behaviors seen in low-functioning individuals (of all ages) with autism. This review highlights the value of defining sleep profiles for children with ASD and integrating different aspects of their symptom profile to their sleep deficits (and vice versa). In turn, this knowledge will result in novel therapeutic targets and interventions that will hopefully improve long-term outcomes of nearly 1 in 68 individuals affected by this pervasive, developmental disorder.

\footnotetext{
Abbreviations

ABC: Aberrant Behavior Checklist; ADHD: Attention deficit hyperactivity disorder; ADIR: Autism Diagnostic Interview (revised); ADOS: Autism Diagnostic Observation Schedule; ASD-CC: Autism spectrum disorder co-
}

morbid for children; ASD: Autism spectrum disorders; BEDS: Bedtime evaluation of disorders of sleep; BRQ: Bedtime Routines Questionnaire; CARS: Checklist for Autism Spectrum Disorders; CBCL: Child Behavior Checklist; CRQ: Child Routine Questionnaire; CSBQ: Children's Social Behavior Questionnaire; CSHQ: Child Sleep Habit Questionnaire; CSHS: Children's Sleep Hygiene Scale; CSWS: Children's Sleep-Wake Scale; DD: Developmental disability; ESS: Epworth Sleepiness Scale; GARS: Gilliam Autism Rating Scale; GDS: Gordon Diagnostic System; GSI: Gastrointestinal symptoms inventory; HFASD: High-functioning autism spectrum disorder; ID: Intellectual disability; IQ: Intellectual quotient; K-CBCL: Korean Version of Child Behavior Checklist; LFASD: Low-functioning autism; MELC: Mullen Early Learning Composite; MSEL: Mullen Scales of Early Learning; PEQ: Parenting Events Questionnaire; PBS: Pediatric Behavior Scale; PCQ: Parental Concerns Questionnaire; PDD: Pervasive developmental disorder; PPVT: Peabody Picture Vocabulary Test-III; PSG: Polysomnography; PSQ: Parental Sleep Questionnaire; RBSR: Repetitive Behavior Scales-Revised; RRB: Repetitive and restricted behaviours; SCAS-P: Spence Anxiety Scale Parent Version; SD: Sleep diary; SIB-R: Scales of Independent Behavior-Revised; SIB: Self-injurious behavior; SQ: Sleep questionnaire; SSP: Short Sensory Profile; TYP: Typical development; VABC: Vineland Aberrant Behavior Checklist; WISC: Wechsler Intelligence Scale for Children; WPPSI: Wechsler Preschool and Primary School Scale of Intelligence.

\section{Competing interests}

The authors declare that they have no competing interests.

\section{Authors' contributions}

SC wrote the paper with contributions from RC, SWL, SWR, and KMC. All authors read and approved the final manuscript.

\section{Acknowledgements}

We acknowledge the support of a Monash University Australian Post-graduate Award (APA) scholarship awarded to the first author and an Australian Research Council (ARC) Autism Sleep grant awarded to Monash University in support of this research (Grant number: DP120101414).

\section{Author details}

${ }^{1}$ School of Psychological Sciences, Faculty of Biomedical and Psychological Sciences, Monash University, Melbourne, Australia. ${ }^{2}$ School of Health Sciences, Royal Melbourne Institute of Technology, Melbourne, Australia. ${ }^{3}$ Division of Sleep and Circadian Disorders, Brigham and Women's Hospital, Boston, USA. ${ }^{4}$ Division of Sleep Medicine, Harvard Medical School, Boston, USA.

Received: 25 June 2014 Accepted: 26 November 2014

Published: 11 December 2014

\section{References}

1. American Psychiatric Association: Diagnostic and Statistical Manual of Mental Disorders (DSM-V). 5th edition. Arlington: American Psychiatric Association; 2013.

2. Baio J: Prevalence of autism spectrum disorder among children aged 8 years-Autism and Developmental Disabilities Monitoring Network, 11 Sites, United States, 2010. Suveillance Summ 2014, 63:1-21.

3. Comprehensive and Coordinated Efforts for the Management of Autism Spectrum Disorders. http://apps.who.int/gb/ebwha/pdf_files/EB133/B133_4en.pdf.

4. Meltzer $L$, Mindell JA: Behavioral sleep disorders in children and adolescents. Sleep Med Clin 2008, 3:269-279.

5. Reynolds AM, Malow BA: Sleep and autism spectrum disorders. Pediatr Clin North Am 2011, 58:685-698.

6. Stores $G$, Wiggs L: Abnormal sleep patterns associated with autism: a brief review of research findings, assessment methods and treatment strategies. Autism 1998, 2:157-169.

7. Park S, Cho S-C, Cho IH, Kim B-N, Kim J-W, Shin M-S, Chung U-S, Park T-W, Son J-W, Yoo HJ: Sleep problems and their correlates and comorbid psychopathology of children with autism spectrum disorders. Res Autism Spectr Disord 2012, 6:1068-1072.

8. Tudor ME, Hoffman CD, Sweeney DP: Children with autism: sleep problems and symptom severity. Focus Autism Dev Disabil 2012, 27:254-262. 
9. Henderson JA, Barry TD, Bader SH, Jordan SS: The relation among sleep, routines, and externalizing behavior in children with an autism spectrum disorder. Res Autism Spectr Disord 2011, 5:758-767.

10. Goldman SE, McGrew S, Johnson KP, Richdale AL, Clemons T, Malow BA: Sleep is associated with problem behaviors in children and adolescents with autism spectrum disorders. Res Autism Spectr Disord 2011 5:1223-1229.

11. Charman $T$, Jones $C R$, Pickles A, Simonoff E, Baird G, Happe F: Defining the cognitive phenotype of autism. Brain Res 2011, 1380:10-21.

12. Chuileann S, Quigley J: Assessing recollection and familiarity in low functioning autism. J Autism Dev Disord 2013, 43:1406-1422.

13. Kanne S, Gerber A, Quirmbach L, Sparrow S, Cicchetti D, Saulnier C: The role of adaptive behaviour in autism spectrum disorders: implications for functional outcome. J Autism Dev Disord 2011, 41:1007-1018.

14. Lovullo SV, Matson JL: Comorbid psychopathology in adults with autism spectrum disorders and intellectual disabilities. Res Dev Disabil 2009, 30:1288-1296.

15. Matson $\mathrm{L}$, Rivet $\Pi$ : Characteristics of challenging behaviours in adults with autistic disorder, PDD-NOS, and intellectual disability. J Intellect Dev Disabil 2008, 33:323-329.

16. Cortesi F, Giannotti F, Ivanenko A, Johnson K: Sleep in children with autistic spectrum disorder. Sleep Med 2010, 11:659-664.

17. Sajith S, Clarke D: Melatonin and sleep disorders associated with intellectual disability: a clinical review. J Intellect Disabil Res 2007, 51:2-13.

18. Hollway JA, Aman MG: Sleep correlates of pervasive developmental disorders: a review of the literature. Res Dev Disabil 2011, 32:1399-1421.

19. Matson JL, Ancona M, Wilkins J: Sleep disturbances in adults with autism spectrum disorders and severe intellectual impairments. J Ment Health Res Intellect Disabil 2008, 1:129-139.

20. Liu X, Hubbard JA, Fabes RA, Adam JB: Sleep disturbances and correlates of children with autism spectrum disorders. Child Psychiatr Human Dev 2006, 37:179-191.

21. American Academy of Sleep Medicine: International Classification of Sleep Disorders: Diagnostic \& Coding Manual, ICSD-3. 3rd edition. Darien: American Academy of Sleep Medicine; 2014.

22. Allik E, Larsson JO, Smedje H: Sleep patterns in school aged children with Asperger syndrome or high functioning autism: a follow up study. J Autism Dev Disord 2008, 38:1625-1633.

23. Adams H, Matson $J L$, Cervantes P, Goldin R: The relationship between autism symptom severity and sleep problems: should bi-directionality be considered? Res Autism Spectr Disord 2014, 8:193-199.

24. Wiggs L, Stores $G$ : Sleep patterns and sleep disorders in children with autistic spectrum disorders: insights using parent report and actigraphy. Dev Med and Child Neuro 2004, 46:372-380.

25. Malow B, Marzec M, McGrew S, Wang L, Henderson L, Stone W: Characterizing sleep in children with autism spectrum disorders: a multi-dimensional approach. Sleep 2006, 29:15-63.

26. Goodlin-Jones BL, Tang K, Liu J, Anders TF: Sleep patterns in preschool-age children with autism, developmental delay and typical development. J Am Acad Child Adolesc Psychiatry 2008, 47:932-940.

27. Krakowiak P, Goodlin-Jones B, Hertz-Picciotto I, Croen LA, Hansen RL: Sleep problems in children with autism spectrum disorders, developmental delays and typical development: a population based study. J Sleep Res 2008, 17:197-206

28. Souders MC, Mason TB, Valladares O, Bucan M, Levy SE, Mandell D, Weaver TE, Pinto-Martin J: Sleep behaviors and sleep quality in children with autism spectrum disorders. Sleep 2009, 32:1566-1578.

29. Anders TF, losif AM, Schwichtenberg AJ, Tang K, Goodlin-Jones BL: Sixmonth sleep-wake organization and stability in preschool-age children with autism, developmental delay, and typical development. Behav Sleep Medic 2011, 9:92-106.

30. Giannotti F, Cortesi F, Cerquiglini A, Vagnoni C, Valente D: Sleep in children with autism with and without autistic regression. J Sleep Res 2011, 20:338-347.

31. Sivertsen B, Posserud MB, Gillberg C, Lundervold AJ, Hysing M: Sleep problems in children with autism spectrum problems: a longitudinal population-based study. Autism 2012, 16:139-150.

32. Baker M, Richdale A, Short M, Gradisar M: An investigation of sleep patterns in adolescents with high-functioning autism spectrum disorder compared with typically developing adolescents. Dev Neurorehabil 2013, 16:155-165.
33. Hering E, Epstein R, Elroy S, lancu D, Zelnik N: Sleep patterns in autistic children. J Autism Dev Disord 1999, 29:143-147.

34. Doo S, Wing YK: Sleep problems of children with pervasive developmental disorders: correlation with parental stress. Dev Med Child Neurol 2006, 48:650-655.

35. Schreck KA, Mulick JA: Parental report of sleep problems in children with autism. J Autism Dev Disord 2000, 30:127-135.

36. Goldman SE, Richdale AL, Clemons T, Malow BA: Parental sleep concerns in autism spectrum disorders: variations from childhood to adolescence. J Autism Dev Disord 2012, 42:531-538.

37. Giannotti F, Cortesi F, Cerquiglini A, Miraglia D, Vagnoni C, Sebastiani T, Bernabei P: An investigation of sleep characteristics, EEG abnormalities and epilepsy in developmentally regressed and non-regressed children with autism. J Autism Dev Disord 2008, 38:1888-1897.

38. Tordjman S, Najjar I, Bellissant E, Anderson G, Barburoth M, Cohen D, Jaafari N, Schischmanoff O, Fagard R, Lagdas E, Kermarrec S, Ribardiere S, Botbol M, Fougerou C, Bronsard G, Vernay-Leconte J: Advances in the research of melatonin in autism spectrum disorders: literature review and new perspectives. Int J Mol Sci 2013, 14:20509-20542.

39. Hayashi E: Effect of melatonin on sleep-wake rhythm: the sleep diary of an autistic male. Psychiatr Clin Neurosci 2000, 54:383-384.

40. Segawa M: Epochs of development of the sleep-wake cycle reflect the modulation of the higher cortical function particular for each epoch. Sleep Biologi Rhythms 2006, 4:4-15.

41. Richdale AL, Schreck KA: Sleep problems in autism spectrum disorders: prevalence, nature, \& possible biopsychosocial aetiologies. Sleep Med Rev 2009, 13:403-411.

42. Glickman G: Circadian rhythms and sleep in children with autism. Neuroscience Biobehav Rev 2010, 34:755-768.

43. Tordjman S, Anderson G, Bellissant E, Botbol M, Charbuy H, Camus F, Graignic R, Kermarrec S, Fougerou C, Cohen D, Touitou Y: Daytime and nighttime excretion of 6-sulphatoxymelatonin in adolescents and young adults with autistic disorder. Psychoneuroendocrinology 2012, 37:1990-1997.

44. Leu RM, Beyderman L, Botzolakis EJ, Surdyka K, Wang L, Malow B: Relation of melatonin to sleep architecture in children with autism. J Autism Dev Disord 2011, 41:427-433.

45. Miyamoto A, Oki J, Takahashi S, Okuno A: Serum melatonin kinetics and long-term melatonin treatment for sleep disorders in Rett syndrome. Brain Dev 1999, 21:59-62

46. Yamashita Y, Matsuishi T, Murakami Y, Kato H: Sleep disorder in Rett syndrome and melatonin treatment. Brain Dev 1999, 21:570.

47. Mannion A, Leader G, Healy O: An investigation of comorbid psychological disorders, sleep problems, gastrointestinal symptoms and epilepsy in children and adolescents with autism spectrum disorder. Res Autism Spectr Disord 2013, 7:35-42.

48. Malow B: Sleep disorders, epilepsy and autism. Ment Retard Dev Disab Res Rev 2004, 10:122-125.

49. Tureck K, Matson JL, May A, Turygin N: Externalizing and tantrum behaviours in children with ASD and ADHD compared to children with ADHD. Dev Neurorehabil 2013, 16:52-57.

50. Richdale AL, Baker E, Short M, Gradisar M: The role of insomnia, pre-sleep arousal and psychopathology symptoms in daytime impairment in adolescents with high functioning autism spectrum disorder. Sleep Med 2014, 15:1082-1088.

51. Knight R, Johnson C: Using behavioural treatment package for sleep problems in autism spectrum disorders. Child Fam Behav Ther 2014, 36:204-221.

52. Cortesi F, Giannotti F, Sebastiani T, Panunzi S, Valente D: Controlled-release melatonin, singly and combined with cognitive behavioural therapy for persistent insomnia in children with autism spectrum disorders: a randomised placebo control trial. J Sleep Res 2012, 21:700-709.

53. Doge N, Wilson G: Melatonin for treatment of sleep disorders in children with developmental disabilities. J Child Neurol 2001, 16:581-584.

54. Goldman S, Adkins K, Calcutt M, Cater M, Goodpaster R, Wang L, Shi Y, Burgess $\mathrm{H}$, Hachey D, Malow B: Melatonin in children with autism spectrum disorders: endogenous and pharmacokinetic profiles in relation to sleep. J Autism Dev Disord 2014, 44:2525-2535.

55. Rossignol DA, Frye RE: Melatonin in autism spectrum disorders: a systematic review and meta-analysis. Dev Med Child Neurol 2011, 53:783-792. 
56. Damaiani J, Sweet B, Sohoni P: Melatonin: an option for managing sleep disorders in children with autism spectrum disorder. Am J Health Syst Pharm 2014, 71:95-101.

57. Grigg-Damberger M, Ralls F: Treatment strategies for complex behavioral insomnia in children with neurodevelopmental disorders. Curr Opin Pulmin Med 2013, 19:616-625.

58. Weiskop S, Richdale AL, Mathews J: Behavioural treatment to reduce sleep problems with autism and fragile X syndrome. Develop Med Child Neurol 2005, 47:94-104.

59. Malow B, Adkins K, Reynolds AM, Weiss S, Loh A, Fawkes D, Katz T, Goldman S, Madduri N, Hundley R, Clemons T: Parent based sleep education for children with autism spectrum disorders. J Autism Develop Disord 2014, 44:216-228.

60. Gregory AM, Sadeh A: Sleep, emotional and behavioral difficulties in children and adolescents. Sleep Med Rev 2012, 16:129-136.

61. Chen F, Lemonnier E, Lazartigues A, Plache P: Sleep problems and information processing, a "disconnection effect" in autism? Med Hypotheses 2006, 66:1245-1246.

62. Schreck K, Mulick JA, Smith AF: Sleep problems as possible predictors of intensified symptoms of autism. Res Dev Disabil 2004, 25:57-66.

63. Williams $P$, Sears $L$, Allard A: Sleep problems in children with autism. J Sleep Res 2004, 13:265-268.

64. DeVincent CJ, Gadow KD, Delosh D, Geller L: Sleep disturbance and its relation to DSM-IV psychiatric symptoms in preschool-age children with pervasive developmental disorder and community controls. J Child Neurol 2007, 22:161-169.

65. Goodlin-Jones B, Tang K, Liu J, Anders TF: Sleep problems, sleepiness and daytime behavior in preschool-age children. J Child Psychol Psychiatr 2009, 50:1532-1540

66. Mayes SD, Calhoun SL: Variables related to sleep problems in children with autism. Res Autism Spectr Disord 2009, 3:931-941.

67. Goldman SE, Surdyka K, Cuevas R, Adkins K, Wang L, Malow BA: Defining the sleep phenotype in children with autism. Dev Neuropsychol 2009, 34:560-573.

68. Moon EC, Corkum P, Smith IM: Case study: a case-series evaluation of a behavioral sleep intervention for three children with autism and primary insomnia. J Pediatr Psychol 2011, 36:47-54.

69. Rzepecka H, McKenzie K, McClure I, Murphy S: Sleep, anxiety and challenging behaviour in children with intellectual disability and/or autism spectrum disorder. Res Dev Disabil 2011, 32:2758-2766.

70. Sikora DM, Johnson K, Clemons T, Katz T: The relationship between sleep problems and daytime behavior in children of different ages with autism spectrum disorders. Pediatrics 2012, 130(Suppl 2):S83-\$90.

71. Anders T, losif AM, Schwichtenberg AJ, Tang K, Goodlin-Jones B: Sleep and daytime functioning: a short-term longitudinal study of three preschool-age comparison groups. A J Intell Dev Disabil 2012, 117:275-290.

72. Taylor MA, Schreck KA, Mulick JA: Sleep disruption as a correlate to cognitive and adaptive behavior problems in autism spectrum disorders. Res Develop Disabil 2012, 33:1408-1417.

73. Hollway JA, Aman MG, Butter E: Correlates and risk markers for sleep disturbance in participants of the autism treatment network. J Autism Dev Disord 2013, 43:2830-2843.

74. Schwichtenberg AJ, Young GS, Hutman T, losif AM, Sigman M, Rogers SJ, Ozonoff S: Behavior and sleep problems in children with a family history of autism. Autism Res 2013, 6:169-176.

75. May T, Cornish KM, Conduit R, Rajaratnam SW, Rinehart NJ: Sleep in high functioning children with autism: longitudinal developmental change and associations with behavior problems. Behav Sleep Med 2013, 12:1-17.

76. Hodge D, Parnell AMN, Hoffman CD, Sweeney DP: Methods for assessing sleep in children with autism spectrum disorders: a review. Res Autism Spectr Disord 2012, 6:1337-1344.

77. Guenole F, Godbout R, Nicolas A, Franco P, Claustrat B, Baleyte JM: Melatonin for disordered sleep in individuals with autism spectrum disorders: systematic review and discussion. Sleep Med Rev 2011, 15:379-387.

78. Kotagal S, Broomall E: Sleep in children with autism spectrum disorder. Pediatr Neurol 2012, 47:242-251.
79. Mindell JA, Meltzer LJ, Carskadon MA, Chervin RD: Developmental aspects of sleep hygiene: findings from the 2004 national sleep foundation sleep in America Poll. Sleep Medicine 2009, 10:711-779.

80. Matson JL, Wilkins J, Macken J: The relationship of challenging behaviours to severity and symptoms of autism spectrum disorders. J Ment Health Res Intellect Disabil 2009, 2:29-44.

doi:10.1186/1866-1955-6-44

Cite this article as: Cohen et al:: The relationship between sleep and behavior in autism spectrum disorder (ASD): a review. Journal of Neurodevelopmental Disorders 2014 6:44

\section{Submit your next manuscript to BioMed Central and take full advantage of:}

- Convenient online submission

- Thorough peer review

- No space constraints or color figure charges

- Immediate publication on acceptance

- Inclusion in PubMed, CAS, Scopus and Google Scholar

- Research which is freely available for redistribution

Submit your manuscript at www.biomedcentral.com/submit
C) BioMed Central 